\title{
AN ANALYSIS OF CLINICAL PROFILE AND INVESTIGATIONS OF THE LIVER METASTASIS FROM VARIOUS GASTROINTESTINAL MALIGNANCIES
}

\author{
R. Srikanth ${ }^{1}$, R. Soundarapandiyan², V. Udhayasankar ${ }^{3}$ \\ ${ }^{1}$ Assistant Professor, Department of General Surgery, Government Vellore Medical College, Vellore. \\ 2Professor, Department of General Surgery, Government Vellore Medical College, Vellore. \\ 3Junior Resident, Department of General Surgery, Government Vellore Medical College, Vellore.
}

\section{ABSTRACT}

\section{BACKGROUND}

Metastatic malignant tumours of the Liver are common in clinical practice, ranking second only to cirrhosis as a cause of fatal liver disease. At autopsy, 30-50\% of all patients dying from malignant diseases reveal hepatic secondaries.

\section{MATERIALS AND METHODS}

Liver metastases are 7 times commoner due to gastrointestinal primary cancers than other tumours. Patients with Liver metastasis due to GI Tract malignancies included in this study, so extra gastrointestinal causes have been excluded from this study.

\section{RESULTS}

$60 \%$ of liver metastases in this study is secondary to colorectal primary cancers. $96 \%$ of liver metastases are Adenocarcinomatous origin form GI tract. 2\% i.e., one case of squamous cell carcinoma of oesophagus and 2\% i.e., one case of NHL from small intestine. Female sex predominates as $60 \%$ of overall cases with liver secondaries. Average duration of illness before presentation and diagnosis is more in females than males. $96 \%$ of these metastases are exclusively from adenocarcinomas.

\section{CONCLUSION}

The surgical management of patients with hepatic metastases involves sorting through many variables and choosing an optimal course of action and utilizing technological advances which will continue to improve the outcome for these unfortunate patients with previously hopeless condition

\section{KEYWORDS}

Liver Metastasis, Colorectal Cancer, Hepatic Resection.

HOW TO CITE THIS ARTICLE: Srikanth R, Soundarapandiyan R, Udhayasankar V. An analysis of clinical profile and investigations of the liver metastasis from various gastrointestinal malignancies. J. Evolution Med. Dent. Sci. 2017;6(11):821-826, D0I: $10.14260 /$ Jemds/2017/179

\section{BACKGROUND}

Residing at the cross roads between the digestive tract and the rest of the body, the liver has the enormous job of maintaining the body's homeostasis. Hence, it acts as the vital sentinel port between the portal system and the general circulation such that it filters, metabolizes and detoxifies the still untamed and obnoxious chemicals from the GI tract.

As the sentinel guard, it becomes the scapegoat in the body's defensive mechanisms against 'the micrometastatic shower' from the various the malignant tumours in the catchment area of the portal circulation. ${ }^{1}$

Metastatic malignant tumours of the Liver are common in clinical practice, ranking second only to cirrhosis as a cause of fatal liver disease. At autopsy, 30-50\% of all patients dying from malignant diseases reveal hepatic secondaries.

Financial or Other, Competing Interest: None.

Submission 13-01-2017, Peer Review 25-01-2017,

Acceptance 28-01-2017, Published 06-02-2017.

Corresponding Author:

Dr. R. Srikanth,

Assistant Professor,

Government Vellore Medical College Hospital,

Vellore-632011

Tamilnadu.

E-mail: srirangalaya@gmail.com

DOI: $10.14260 /$ jemds $/ 2017 / 179$
Hence surgical Management of hepatic metastasis has become important in the care of cancer patients.

Although half of all the patients dying from cancer disease reveal hepatic metastases, advances in hepatic resection and regional anticancer therapies have produced measurable benefits in many of these cases. ${ }^{2}$

Thus, surgeons are increasingly called upon for reassessment and management of these patients, not only for palliation but even with the intention of cure, fortunately in colorectal malignancy which is one among the top five killer cancers of the world.

\section{Justification for this Study}

$50 \%$ of all patients dying form cancers are shown to have liver metastases and most of them have succumbed to this killer disease due to direct or indirect consequences of the liver metastases.

Liver metastases are 7 times commoner due to gastrointestinal primary cancers than other tumours. So extra gastrointestinal causes have been excluded from this study. Furthermore, the universally accepted belief is that surgical resection is indicated for metastases from colorectal and GI carcinoid tumours only and beyond any scientific doubt.

Hence, this study on 'Liver metastases' from 'Gastrointestinal primary tumours only' has been selected as a dissertation for the examination in General surgery. 


\section{Objectives}

The AIMS of this study on" the Liver Metastasis from various Gastrointestinal cancers" are following-

- To analyse patients' clinical profiles in various gastrointestinal cancers which metastasize to the liver.

- To analyse the distribution among various primary gastrointestinal malignant tumours which commonly metastasize to the liver.

- To analyse the pattern of abnormal biochemistry in the patients with liver metastases.

- To analyse the accuracy of different Imaging modalities in investigating the patients with liver metastases.

- To analyse in toto, the different variables like patients', clinical profile, Biochemical tests and Imaging modalities, in predicting the respectability of hepatic metastases from multitude of GI primary cancers.

\section{MATERIALS AND METHODS}

\section{Selection of the Patients}

All the patients who were included in this study had the confirmed diagnosis of the hepatic metastasis secondary to the known primary cancers anywhere in the gastrointestinal system. They were admitted and managed in the surgical wards of Government Vellore Medical College Hospital, Vellore, during the period between December 2013 to November 2016. Ethical Clearance obtained from the Institutional ethical committee.

All the patients underwent thorough physical examination and relevant and available investigations. Cases with the diagnosis of primary Liver tumours and liver secondaries from extra gastrointestinal systems were excluded from this study.

\section{RESULTS}

\section{Observations with Statistics}

The following is the list of primary cancers from gastrointestinal tract in the order of frequency, which have given rise to the hepatic secondaries (Total cases 50).

(See the Pie chart)

1. Colorectal adenocarcinomas

(30) $60 \%$

2. Gastric Adenocarcinomas

(12) $24 \%$

3. Gall bladder carcinomas

(2) $4 \%$

4. Pancreatic Adenocarcinomas

(2) $4 \%$

5. Oesophageal carcinomas

(Squamous Cell Ca-1

+Adenocarcinomas -1)

(2) $4 \%$

6. Non. Hodgkin's Lymphoma of Small Intestine

7. Multiple liver secondaries with Ascites (Unknown primary)

Total

(1) $2 \%$

$50 \quad 100 \%$

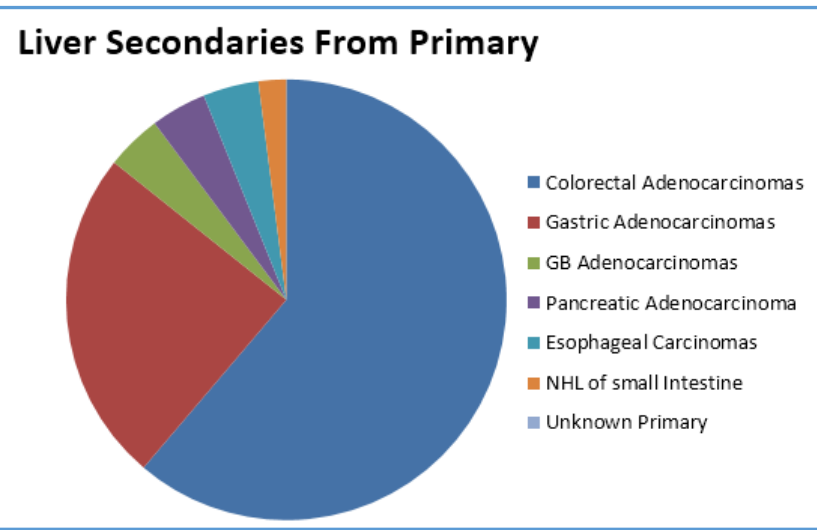

Sex Ratio

$\mathrm{M}: \mathrm{F}=2: 3$

Range, Mean, Average Values of Age (See the Bar chart)

Range - 28 years to 70 years.

Average - 54.88 corrected 55 years.

Mean value - 56 years.

\section{Decade Wise Grouping}

$21-30-1$

$31-40-3$

$41-50-12$

$51-60-19$

$61-70-15$

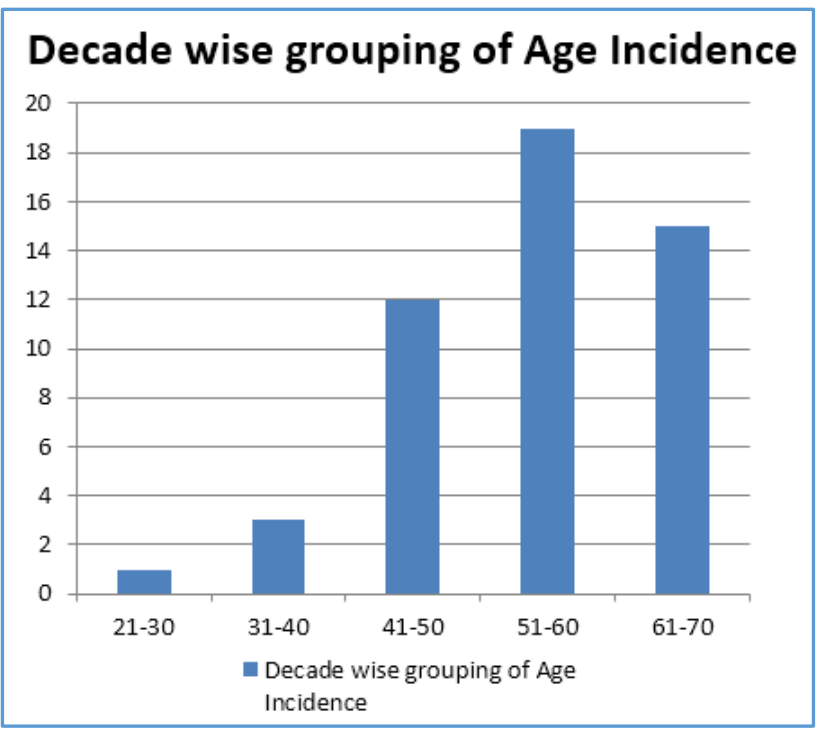

\section{Case Presentations}

Only with chief complaints of primary tumours without liver symptoms.

- 17 out of $50=34 \%$.

- Only with chief complaints of liver metastases without primary tumours' symptoms.

- Synchronous + Metachronous. (After investigation primary is diagnosed)

(1) $+(2)=6 \%$

- Chief complaints indicating both primary and liver pathology.

- 30 out of 50 .

- All those complaining of symptoms relating to primary. 47 out of $50=94 \%$. 
- Synchronous versus Metachronous lesions. 48:2 i.e. $96 \%$ : $4 \%$

- Synchronous presentation of liver secondaries $96 \%$ and Metachronous lesions are $=4 \%$.

- Range, Mean, Average duration of symptoms at presentation in months.

- $\quad$ Range $1 \frac{1}{2}$ month to 24 months.

- $\quad$ Average (7.22) months.

- Mean 6 months.

- Only in colorectal cancers.

- Average - 8 months.

- In males Average - 5.5 months.

- In Females Average - 8 Months.

List of Commonest Localizing Signs of Liver Pathology

1. Hepatomegaly hard and irregular

$29 / 50=58 \%$

2. (R) Hypochondrial pain

3. Ascites

4. Jaundice

5. Fever (PUO)

$24 / 50=48 \%$

$15 / 50=30 \%$

$5 / 50=10 \%$

$3 / 50=6 \%$

Cases which have other extra hepatic metastases along with liver lesions $-15 / 30=30 \%$.

\section{Liver Function Status Commonest Deranged Parameter}

1. $\uparrow$ Serum alkaline phosphatase $\quad 32 / 50=64 \%$

2. $\uparrow$ Bilirubin $5 / 50=10 \%$

3. $\uparrow$ SGPT $5 / 50=10 \%$

4. $\downarrow$ Total protein $\quad 6 / 50=12 \%$

5. $\downarrow$ Albumin: globulin ratio $\quad 1 / 50=2 \%$

\section{Carcinoembryonic Antigen Levels}

- Available only for Six Patients.

- Elevated in 5 patients.

- $\quad$ All of them are colorectal primary cancers.

- Two among them had metachronous liver secondaries.

- Diagnostic Modalities Abdominal ultrasound done in all cases and found to be positive in $33 / 50=66 \%$ of cases. Remaining (other cases) i.e. 17/50 were shown to have liver secondaries either by enhanced CT scan or in open laparotomy.

- $\quad$ CT Scan Abdomen with contrast enhancement.

- Done only in 10 cases.

- CT Scan had shown positive liver secondaries in $9 / 10=$ $90 \%$ of times.

- And missed in one case which was defected in open laparotomy.

- $\quad$ Laparotomy done for surgery of primary tumour $39 / 50$ $=78 \%$ of cases not done in $11 / 50=22 \%$ of cases due to extensive/ advanced systemic disease.

- Multiple metastases in liver i.e. more than 3 lesions detected by all the above modalities 35/50 $=70 \%$.

- Cases with metastases $\leq 3$ lesions (by all methods)

- $15 / 50=30 \%$

- Among colorectal cancers $\leq 3$ lesions.

- $13 / 30=43 \%$.

- Colorectal primaries with $\leq 3$ liver metastatic lesions and without other significant extrahepatic metastases $6 / 30=$ $20 \%$.
DISCUSSION

Analytical Statements

$60 \%$ of liver metastases in this study is secondary to colorectal primary cancers.

$96 \%$ of liver metastases are Adenocarcinomatous origin form GI tract. $2 \%$ i.e. one case of squamous cell carcinoma of oesophagus and $2 \%$ i.e. one case of NHL from small intestine.

Female sex predominates as $60 \%$ of overall cases with liver secondaries. Average duration of illness before presentation and diagnosis is more in females than males (F: $\mathrm{M}=8$ months).

Chief compliant at presentation is related to the primary cancer (94\%).

Liver metastasis presenting only with liver symptoms (i.e. without complaints of primary) is only $6 \%$ (i.e. 3 out of 50 case) even within this group, only one case presented only with liver related symptom of (R) hypochondrial pain. After further evaluation per primary was found as carcinoma caecum after colonoscopy as well as in Barium enema.

But $66 \%$ of all cases complains of liver related symptoms along with other symptoms related to the primary tumours. In this study, only $4 \%$ cases (i.e. 2 cases) had metachronous liver lesions following the surgery for primary cancers.

Both the cases had colorectal malignancies operated 7 and 9 months earlier to the current presentation.

They had regular quarterly follow up and both cases presented with progressing Ascites which on further evaluation showed elevated CEA levels and multiple liver secondaries by ultrasound examination.

Average duration of History of illness at diagnosis is 8 months in colorectal primaries, males present earlier than female patients (Males at 5.5 months and females at 8th month).

Commonest physical finding at presentation is hard and irregular hepatomegaly (58\%) then (R) hypochondrial pain (48\%) and ascites in $30 \%$ of cases But Jaundice which is a sign of liver functional impairment is rare (only in $10 \%$ cases) (out 5 cases with jaundice, 4 had obstructive lesion and other one $\mathrm{h}$ ad comorbid alcoholic cirrhosis (decompensated).

30 cases have other extrahepatic metastases as very advanced systemic diseases extrahepatic metastases has reduced the chance of otherwise resectability of colorectal liver metastases from $43 \%$ to $20 \%$

The commonest of liver function test found to be abnormal in this study is increased serum alkaline phosphatase, (64\%). Other significant finding of reversed Albumin: Globulin ratio indicating severe liver failure was found only in one case of Ca pancreas whose liver was already in decompromised state due to alcoholic cirrhosis. Though the test for carcinoembryonic antigen level in serum is restricted in availability, it was found to be raised in all cases of colorectal primaries with liver secondaries for whom it was done.

Only one case $(2 \%)$ presented with liver secondaries in advanced stage whose primary could not be detected (though he complained of passing blood per anus. Due to moribund condition because of other concurrent systemic metastases such as lung secondaries, he died within few days of admission before detailed evaluation. 
Conventional ultrasound examination of liver scan picks up liver secondaries only in $66 \%$ of cases and also it can underestimate the number of hepatic lesions actually present. Contrast enhanced CT Scan (Dynamic CT Scan) Scan pick up $90 \%$ of liver secondaries but its availability is restricted for practice.

$70 \%$ of all the cases had multiple liver lesions (i.e. $\geq 4$ lesions) and $57 \%$ of colorectal primaries had multiple lesions in liver which could preclude any curative resection.

Only 6 out of 50 cases, all of them are with colorectal primaries may benefit from liver resection. (i.e. $20 \%$ of all colorectal primaries).

\section{In Summary}

$60 \%$ of all patients with liver secondaries from multitude of GI tract primaries are from colorectal adenocarcinomas. This pattern of distribution has been shown in many reviews.

$96 \%$ of these metastases are exclusively from adenocarcinomas. This finding is similar to other standard references.

The dynamic CT scan is $90 \%$ accurate in diagnosing liver secondaries but its availability is restricted in practice. But the finding of accuracy in detecting this disease by ultrasound is $60 \%$ which is similar to the general review.

Lastly, the respectability of liver secondaries from primary colorectal adenocarcinomas is found to be possible in $20 \%$ of patients. Though this figure is within the range of International and advanced countries, it could be reduced by the availability and application of better imaging modalities like Intraoperative ultrasound and CT-Portography.

The fatal liver disease due to extensive liver secondaries is common in clinical practice, ranking second only to cirrhosis as a cause.

The incidence of clinically significant metastatic tumours of liver is 12-20 times commoner than that of primary carcinoma of the liver. ${ }^{3}$

Hepatic secondaries in patients dying from malignant diseases are found to be present in $30-50 \%$ of cases at autopsy. 4

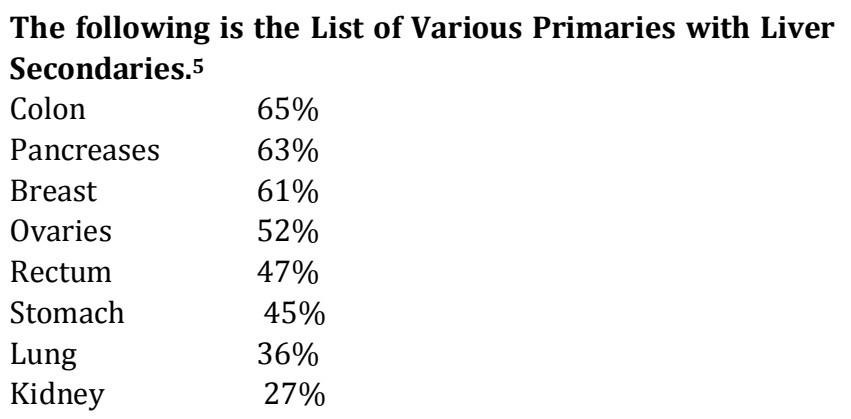

$80-90 \%$ of hepatic resection for metastatic liver diseases are for colorectal cancers.

Despite effective and efficient screening programmes in advanced Western countries, synchronous hepatic metastases continue to be found in $15-25 \%$ of cases of colorectal cancers at the time of initial diagnosis. ${ }^{6}$

In addition, $40-50 \%$ of patients who underwent treatment for primary colorectal cancer shall develop metachronous liver secondaries. ${ }^{7}$

One third of all patients with liver secondaries is due to colorectal cancers will have their disease restricted to the liver and hence may be amenable to resection and/or local treatment. 8

Mean survival period for patients with liver metastases in colorectal cancer is ranging from 3-24 months in untreated cases.

Virtually all solid malignancies may metastasize to the liver except the primary brain tumours.

Only 1 in 6 patients with colorectal cancer with hepatic secondaries who are suitable for hepatic resection and consequent long term survival are undergoing such treatments even in economically advanced countries like USA, hence, there is enormous chance for decrease in mortality rate for colorectal malignancies with widespread practice of timely hepatic resection. ${ }^{9}$

Modern surgery of the liver is dependent on the concepts initiated by Couinaud and (1957) and developed by Ton That Tung and Bismuth.

Surgical Anatomy of the liver based on precise knowledge of its natural divisions and complete understanding of these basic components is an essential requisite for any surgeon who is performing an operation on the liver.

\section{These Concepts are examined in Two Aspects-}

Morphological Anatomy: what is conventionally seen in laparotomies and cadaveric specimens

Functional anatomy: Although seemingly complex, this concept which was thoroughly enumerated by Couinaud is the most exact and complete description of liver anatomy and has useful application for the functional aspects of liver surgeries.

Segmental liver anatomy based on the distribution of glissonian pedicles and the hepatic veins has been the foundation of the modern hepatic surgery.

Liver is being divided into eight segments, each segment being considered as functional unit with a branch of hepatic artery, portal vein and bile duct and $a b$ ranch of hepatic vein. The natural history of various malignancies and the underlying biologic steps in tumour progression are becoming more clearly characterized

\section{Tumor Characters}

In addition to loss of proliferative control, tumour cells must acquire imbalances in regulation of motility, adhesion and stromal proteolysis in order to become competent for invasion and metastasis.

The cell surface protein encoded by the tumour suppressor gene DCC plays a significant role in this process. Its loss correlates with advanced invasiveness and metastasis in patients with colon and pancreatic cancers.

\section{Target Tissue Characters}

Tumour adhesion to organ specific endothelial and parenchymal cell structures. CEA is one of the molecules which contribute to metastatic specificity.

\section{Load of Micrometastasis}

Due to the reason that liver is the sentinel receiver of portal venous blood, it is most vulnerable for secondaries from the catchment areas of portal circulation - GI tract. 


\begin{tabular}{|c|c|c|}
\hline $\begin{array}{c}\text { Sl. } \\
\text { No. }\end{array}$ & $\begin{array}{c}\text { Sonographic } \\
\text { Patterns }\end{array}$ & General Association \\
\hline 1 & $\begin{array}{c}\text { Echogenic Metastases } \\
\text { (Hypervascular) }\end{array}$ & $\begin{array}{c}\text { • Gastrointestinal origin } \\
\text { - Renal cell carcinoma } \\
\text { - Carcinoid, Choriocarcinoma }\end{array}$ \\
\hline 2 & $\begin{array}{c}\text { Hypoechoic } \\
\text { metastases } \\
\text { (Hypervascular) }\end{array}$ & Lymphomas \\
\hline 3 & $\begin{array}{c}\text { Bull's eye } \\
\text { (Target lesions) }\end{array}$ & Bronchogenic carcinoma \\
\hline 4 & $\begin{array}{c}\text { Calcifications } \\
\text { colon }\end{array}$ \\
\hline 5 & $\begin{array}{c}\text { Cystic metastases } \\
\text { (Rare) }\end{array}$ & $\begin{array}{l}\text { Leiomyosarcoma, } \\
\text { adenocarcinoma of stomach }\end{array}$ \\
\hline \multicolumn{3}{|c|}{ Table 1. Sonographic Features of Metastasis of liver } \\
\hline
\end{tabular}

\begin{tabular}{|c|c|c|}
\hline Technique & Benign Lesions & Malignancy \\
\hline MRI T 2 & $\begin{array}{c}\text { Vessels } \\
\text { Haemangiomas } \\
\text { Cysts } \\
\text { Cysts }\end{array}$ & $\begin{array}{l}\text { Small metastatic } \\
\text { lesions Highly } \\
\text { vascular tumor } \\
\text { (islet cell, renal, } \\
\text { carcinoid) Cystic } \\
\text { tumours } \\
\text { Highly vascular } \\
\text { tumours } \\
\text { (islet cell, renal, } \\
\text { carcinoid) } \\
\end{array}$ \\
\hline CT & $\begin{array}{c}\text { Fatty infiltration } \\
\text { Fatty infiltration } \\
\text { Nonenhanced } \\
\text { vessels } \\
\text { Adenoma } \\
\text { Abscess } \\
\end{array}$ & $\begin{array}{c}\text { Metastases } \\
\text { Hepatocellular } \\
\text { cancer } \\
\text { Metastases }\end{array}$ \\
\hline СТP & $\begin{array}{l}\text { Haemangioma } \\
\text { Cysts } \\
\text { Adenoma } \\
\text { Flow artefacts } \\
\end{array}$ & Metastases \\
\hline Angiography & $\begin{array}{c}\text { Focal nodular } \\
\text { Hyperplasia } \\
\text { Haemangioma }\end{array}$ & Metastases \\
\hline \multicolumn{3}{|c|}{$\begin{array}{c}\text { Table 2. Benign Liver Lesions that may } \\
\text { be confused with Malignancy }\end{array}$} \\
\hline
\end{tabular}

Either FNA or Trucut Liver Biopsy may be used with Image - guided modalities to increase the yield rate

\section{Surgical Guidelines for Hepatic Resection}

The existence of extrahepatic intra- abdominal metastases should be excluded before attempting a hepatic resection. Since the periportal lymph nodes are the most common site for intra-abdominal extra hepatic metastases, they should be biopsied and sent for frozen section. If extrahepatic disease is present, hepatic resection should not be carried out.

The extent of a hepatic resection can span from one small nodule to a trisegmentectomy by which 75 percent of the liver is removed. The assessment of patients for trisegmentectomy is very difficult since no tests are currently available to delineate accurately which patient can survive with a 75 percent loss of liver mass. In general, however, if a patient has cirrhosis, an extensive resection is discouraged.
Debilitate (poor performance status) patients are not good candidates for major hepatic resection. Age alone should not preclude a patient's eligibility for hepatic resection.

\section{Treatment - Non- Surgical Methods}

The following are the various nonsurgical modalities of therapy available for curative as well as palliative course, either alone or with surgical treatment.

1. Chemotherapy:

A. Systemic chemotherapy.

B. Regional chemotherapy.

a. Intrahepatic Arterial Infusion.

b. Portal vein infusion.

2. Hepatic Artery ligation/Embolization/ Ligation of portal vein.

3. Alcohol Injection.

4. Cryosurgery.

5. Radiation Therapy.

6. Immunotherapy.

\section{Preventive Strategies}

Early detection and timely curative treatment of the primary cancers are the ideal preventive measure against secondaries. To achieve the above, widespread and effective implementation of primary preventive and screening programmes particularly against common cancers like colorectal and gastric cancers are warranted.

Screening protocol for metachronous liver secondaries in colorectal carcinoma after curative treatment for primary follows.

\section{CONCLUSION}

This study reveals that $60 \%$ of all patients presenting with the liver metastases from known primary tumours of gastrointestinal system are from colorectal adenocarcinomas. This study also shows higher incidence in females than male patients (3:2) and the average duration of illness at presentation and diagnosis is more in females than the overall average ( 8 months versus 7 months). This could be due to general neglect and delayed seeking of medical services by women.

Inspite of very notable absence of primary preventive/ screening programmes in this community, appreciable and significant number of patients with colorectal cancers - $20 \%$ (who present with less than 10 months duration of illness, less than or equal to 3 liver secondaries and without any extrahepatic involvement qualify for the surgical treatment.

Though this amount of $20 \%$ may further go down when better and essential investigative modalities like CTP and intraoperative ultrasound are made available, a significant number of patients can avail and enjoy the benefits of timely liver surgery if provided.

Though, surgeons and oncologist have always had a fatalistic attitude towards the discovery of liver metastases in any cancer patient, over the last decade, this has changed remarkably in view of more convincing use of surgery and other supporting non-surgical therapies.

So, the surgical management of patients with hepatic metastases involves sorting through a large number of variables and choosing an optimal course of action and utilizing technological advances which will continue to improve the outcome for these unfortunate patients with previously hopeless condition. 


\section{REFERENCES}

[1] Cheon SH, Rha SY, Jeung HC, et al. Survival benefit of combined curative resection of the stomach (D2 resection) and liver in gastric cancer patients with liver metastases. Ann Oncol 2008;19(6):1146-53.

[2] Koga R, Yamamoto J, Ohyama S, et al. Liver resection for metastatic gastric cancer: experience with 42 patients including eight long-term survivors. Jpn J Clin Oncol 2007;37(11):836-42.

[3] Elias D, Cavalcanti de Albuquerque A, Eggenspieler P, et al. Resection of liver metastases from a noncolorectal primary: indications and results based on 147 monocentric patients. J Am Coll Surg 1998;187(5):487-93.

[4] Takada Y, Otsuka M, Seino K, et al. Hepatic resection for metastatic tumors from noncolorectal carcinoma. Hepatogastroenterology 2001;48(37):83-6.
[5] Weitz J, Blumgart LH, Fong Y, et al. Partial hepatectomy for metastases from noncolorectal, nonneuroendocrine carcinoma. Ann Surg 2005;241(2):269-76.

[6] Grobmyer SR, Fong Y, D’Angelica M, et al. Diagnostic laparoscopy prior to planned hepatic resection for colorectal metastases. Arch Surg 2004;139(12):132630.

[7] Petrowsky H, Gonen M, Jarnagin W, et al. Second liver resections are safe and effective treatment for recurrent hepatic metastases from colorectal cancer: a bi-institutional analysis. Ann Surg 2002;235(6):86371.

[8] Choti MA, Sitzmann JV, Tiburi MF, et al. Trends in long term survival following liver resection for hepatic colorectal metastases. Ann Surg 2002;235(6):759-66.

[9] Ng KK, Poon RT. Radiofrequency ablation for malignant liver tumor. Surg Oncol 2005;14(1):41-52. 